\title{
Differences in Reef Fish Assemblages between Populated and Remote Reefs Spanning Multiple Archipelagos Across the Central and Western Pacific
}

\author{
Ivor D. Williams, ${ }^{1}$ Benjamin L. Richards, ${ }^{1}$ Stuart A. Sandin, ${ }^{2}$ \\ Julia K. Baum, ${ }^{3}$ Robert E. Schroeder, ${ }^{4}$ Marc O. Nadon, ${ }^{1}$ Brian Zgliczynski, ${ }^{1}$ \\ Peter Craig, ${ }^{5}$ Jennifer L. McIlwain, ${ }^{6}$ and Russell E. Brainard ${ }^{7}$ \\ ${ }^{1}$ Joint Institute for Marine and Atmospheric Research (JIMAR), University of Hawaii and Coral Reef Ecosystems Division (CRED), \\ Pacific Islands Fisheries Science Center (PIFSC), National Marine Fisheries Service, NOAA, 1125B Ala Moana Boulevard, Honolulu, \\ HI 96814, USA \\ ${ }^{2}$ Center for Marine Biodiversity and Conservation, Scripps Institution of Oceanography, 8750 Biological Grade, La Jolla, \\ CA 92037-0202, USA \\ ${ }^{3}$ National Center for Ecological Analysis and Synthesis, 735 State Street, Suite 300, Santa Barbara, CA 93101, USA \\ ${ }^{4}$ Habitat Conservation Division, Pacific Islands Regional Office, National Marine Fisheries Service, NOAA, 1601 Kapiolani Blvd., \\ Suite 1110, Honolulu, HI 96814, USA \\ ${ }^{5}$ National Park of American Samoa, Pago Pago, AS 96799, USA \\ ${ }^{6}$ Marine Laboratory, University of Guam, Mangilao, GU 96923, USA \\ ${ }^{7}$ Coral Reef Ecosystems Division (CRED), Pacific Islands Fisheries Science Center (PIFSC), NOAA, 1610 Kapiolani Blvd., Suite 1110, \\ Honolulu, HI 96814, USA
}

Correspondence should be addressed to Ivor D. Williams, ivor.williams@noaa.gov

Received 15 June 2010; Accepted 18 August 2010

Academic Editor: Kim Selkoe

Copyright ( $) 2011$ Ivor D. Williams et al. This is an open access article distributed under the Creative Commons Attribution License, which permits unrestricted use, distribution, and reproduction in any medium, provided the original work is properly cited.

Comparable information on the status of natural resources across large geographic and human impact scales provides invaluable context to ecosystem-based management and insights into processes driving differences among areas. Data on fish assemblages at 39 US flag coral reef-areas distributed across the Pacific are presented. Total reef fish biomass varied by more than an order of magnitude: lowest at densely-populated islands and highest on reefs distant from human populations. Remote reefs $(<50$ people within $100 \mathrm{~km}$ ) averaged $\sim 4$ times the biomass of "all fishes" and 15 times the biomass of piscivores compared to reefs near populated areas. Greatest within-archipelagic differences were found in Hawaiian and Mariana Archipelagos, where differences were consistent with, but likely not exclusively driven by, higher fishing pressure around populated areas. Results highlight the importance of the extremely remote reefs now contained within the system of Pacific Marine National Monuments as ecological reference areas.

\section{Introduction}

Recent studies of isolated coral reefs, as well as of historical records, have contributed to a growing awareness of how substantially altered reef fish communities now are around human population centers [1-6]. The greatest difference between populated areas and what are assumed to be largely intact reef systems, at extremely remote locations, tends to be in the abundance and size of large predatory fishes such as sharks and jacks. Those groups often comprise a large portion of total fish biomass estimated from visual surveys at remote coral reefs $[1,2,7]$, but are infrequently encountered and/or constitute a small portion of biomass on reefs close to even fairly small human populations [8]. Human impacts can also be substantial at lower trophic levels, particularly among species targeted by coral reef 
fisheries [8], and the depletion of predators can also lead to what appear to be cascading effects on prey species $[7,9,10]$. There is substantial evidence that relatively low levels of fishing can have profound impacts on coral reef fish assemblages, and that fishing is very likely a major contributor to the differences in reef fish communities between remote and populated coral reefs $[8,11-15]$, but anthropogenic impacts can also manifest themselves through habitat or environmental degradation which in turn reduces the capacity of affected reefs to support abundant marine life $[16,17]$.

While there is a developing consensus that reef fish populations around human population centers tend to be substantially different to those found on isolated reefs, there remains some uncertainties about the generality and normal extent of such differences. To date, studies involving extremely isolated reefs have either been at or below the scale of a single archipelago $[1,2,7]$, or relied on data acquired from multiple studies using a range of sampling methods, survey habitats, and personnel [4]. This study utilizes data on coral reef fish assemblages gathered by a single large-scale program, NOAA's Pacific Reef Assessment and Monitoring Program (Pacific RAMP), that surveys coral reefs at the majority of US flag islands and atolls in the Pacific with shallow water coral reef habitat. The Pacific RAMP therefore spans a spatial range of thousands of kilometers as well as large gradients of potential human impact, from the heavily populated, urbanized, and developed islands of Oahu, Guam, and Saipan, to some of the most isolated reefs in the Pacific such as the uninhabited Howland and Baker Islands which are $>500 \mathrm{~km}$ from the nearest populated area. A particular focus of this study was to quantify the extent of differences in reef fish assemblages between populated and remote reefs at Pacific-wide and within-archipelago scales for a range of trophic, taxonomic, and size-based groupings, and therefore to determine the generality of patterns corresponding with the presence of local human populations. In addition, this study provides information on the status of reef fish assemblages in four US Pacific Marine National Monuments (MNM) surveyed by the Pacific RAMP.

\section{Methods}

2.1. Survey Locations and Survey Program. The Pacific RAMP, conducted by the NOAA Pacific Islands Fisheries Science Center's Coral Reef Ecosystem Division (NOAACRED) and local partners, surveys coral reefs in the Hawaiian and Mariana Archipelagos, American Samoa, and the Pacific Remote Island Areas (PRIA, i.e., Johnston and Wake Atolls and the US Line and Phoenix Islands), and therefore encompasses the majority of all US Pacific islands and territories with shallow coral reef habitats (Figure 1). The 39 island and atolls (henceforth "reef-areas") included in this study (Table 1) comprise all reef areas surveyed by the Pacific RAMP between 2008 and April 2010; that is, after the Pacific RAMP survey design was changed to one based around stratified random sampling of $<30 \mathrm{~m}$ hardbottom habitats, with the additional requirement that survey sites were always separated by at least $100 \mathrm{~m}$. To increase comparability among reef areas, only data from fore reef sites were used. Data from 1,021 sites, constituting around 1,200 hours of underwater observation, were included in this study.

Recognizing that reef fish assemblages at lightly or unpopulated areas can be significantly affected by nearby population centers over scales of at least several tens of kilometers [12], reef areas were classified as either "populated" or "remote" based on a combination of local human population density (measured in terms of human population per unit area of reef, Table 1), proximity to larger population centers, and management status. The intention was to limit the classification of "remote" to reef areas where there was a reasonable expectation that direct human impacts were very low to negligible. All Pacific RAMP survey locations that might feasibly be considered as remote by that definition were over 100 kilometers from the nearest human settlement comprising more than a handful of people. It seems likely that the greatest near-term threat to reef fish assemblages at those locations would come from occasional visitation by fishing operations. Brewer and colleagues found evidence that depletion of fish stocks was related to proximity to provincial capitals (and presumably the larger markets for fish at those mini population centers) over scales of $>50 \mathrm{~km}$ in the Solomon Islands [12]. Given that provincial capitals in the Solomon Islands have much smaller populations than several of the islands included in this study, it seemed plausible that the impacts, in terms of increased fishing pressure, of those larger population centers could be nontrivial over larger distances. Therefore, the criteria for a reef area to be classified as remote were set as (i) local population of $<50$ people; (ii) located $>100 \mathrm{~km}$ from the nearest larger human settlement. Two exceptions were Midway and Wake Atolls, where human population was marginally above 50 but where there were significant restrictions on fishing activities, as described below.

Within the Hawaiian Islands there was a very clear divide between the southern main Hawaiian Islands (MHI: Hawaii Island to Kauai, Figure 1) and the Northwestern Hawaiian Islands (NWHI: French Frigate Shoals to Kure, Figure 1). While there are substantial differences in population density and apparently also in human impacts on reef fish assemblages among the main islands [8], all of the MHI are relatively close to large population centers (Table 1). For example, Niihau, the least populated of the MHI, is little more than $30 \mathrm{~km}$ from Kauai which has a population of $>50,000$. We therefore classified all of the MHI as populated (Table 1). In contrast, French Frigate Shoals, the most southerly of the NWHI covered by this study is $>600 \mathrm{~km}$ from the nearest MHI (Figure 1). Midway Atoll, the only permanently inhabited reef area in the NWHI, with a resident population of around 60 management staff, researchers, and contractors, was a US Navy base until 1993 and has been a US Fish and Wildlife Service (FWS) National Wildlife Refuge (NWR) since 1988. A study based on surveys in 2000-2003 noted that, although sharks were abundant at Midway, jack populations were depleted compared to other reef areas in the NWHI, perhaps due to lingering effects of the four decades that Midway was a military base together 
with possible impacts of a catch and release sport fishery for jacks that operated between 1996 and 2000 [18]. Because of substantial local restrictions on fishing, it was assumed that overall human impacts to the reef fish assemblage would have been relatively minor by the time of our surveys in 2008 . While other of the NWHI are intermittently inhabited by a small number of scientists or managers, the very strong likelihood is that, by virtue of their isolation, direct human impacts on reef fish assemblages in the NWHI have been very limited for a considerable period. In 2005 the State of Hawaii established the NWHI Marine Refuge which closed all state waters to fishing. Protection was further enhanced by the establishment of the Papahānaumokuākea Marine National Monument (PMNM) in 2006. Therefore all of the NWHI, including Midway, were classified as remote (Table 1).

Similarly, the Mariana Archipelago is comprised of a group of mostly inhabited southern islands (Guam to Saipan) and a series of unpopulated or virtually unpopulated northern islands (Sarigan to Farallon de Pajaros [FDP]). All of the southern islands were classified as populated, including Aguijan, which has no resident human population but is nine kilometers from Tinian, and less than $35 \mathrm{~km}$ from the densely populated island of Saipan (Table 1). All of the northern islands from Sarigan to FDP were classified as remote on the basis of no, or extremely small, resident human populations (highest population being six people at Alamagan, Table 1), and that the most southerly of those, Sarigan, is $\sim 150 \mathrm{~km}$ from the nearest population center, Saipan (Figure 1). While it is reasonable to assume that the Mariana reef areas classified as remote were much less directly impacted by human activities than those in the southern part of the archipelago, there is evidence of some intermittent commercial fishing operations in the northern islands and of unquantified levels of poaching by foreign vessels [19]. In addition, geological and physical differences between the southern and northern islands, which include a relatively recent history of volcanic activity at several of the northern islands, have resulted in distinct habitat differences between those two subregions [20], which have the potential to confound differences due to human impacts. In 2009, presidential proclamation 8335 established the Mariana Trench Marine National Monument (MTMNM) which contains the waters around the three northernmost of the Mariana Islands (FDP, Maug, and Asuncion, Figure 1).

The Pacific Remote Island Areas (PRIAs) are made up of US sovereign islands not within the jurisdiction of any US state or territory [21]. The PRIA therefore constitute a diverse and widely separated group of reef areas, including islands and atolls in the Marshall, US Line, and Phoenix Islands (Figure 1). All of the PRIA except Wake Atoll, which is a US Air Force installation, have been managed as NWR by the FWS since 1974 (Howland, Baker, Jarvis), 2001 (Kingman and Palmyra), or 2004 (Johnston Atoll). Five of the PRIA (Johnston, Kingman, Howland, Baker, and Jarvis) are unpopulated, and one, Palmyra, has a research station operated by the Nature Conservancy, which supports a small staff, scientists and visitors. As the coral reefs of Palmyra are within the NWR, harvesting of reef fishes is prohibited. In addition, the PRIA are distant from human population centers: the least remote being Jarvis and Palmyra, which are both around $350 \mathrm{~km}$ from, respectively, Kiritimati and Tabuaeran in the Line Islands chain. The US Air Force installation at Wake Atoll is staffed by $\sim 100$ personnel at any one time. Although the population level at Wake was slightly higher than the criteria we used for "remote" areas, fishing is restricted at Wake by a ban on commercial fishing, the use of traps, most nets, and automated spear guns, and a prohibition on the take of sharks, rays, bumphead parrotfishes (Bolbometopon muricatum) and napoleon wrasse (Cheilinus undulatus). In 2009, all of the PRIA were designated by the Pacific Remote Islands MNM, and all are classified as remote for this study.

Survey data from five reef areas in American Samoa are used in this study (Figure 1). Tutuila is by far the largest and most densely populated (Table 1 ). Approximately $100 \mathrm{~km}$ east of Tutuila are the Manu'a Islands of Ta'u, and Ofu and Olosega (Figure 1, Table 1). The other two locations are Swains Island and Rose Atoll (Figure 1). While there are indications that commercial fishing of reef fishes has declined around Tutuila in the recent past, fishing continues to be an important part of the local culture and is a common recreational and subsistence activity [22]. Population density and, likely, levels of fishing are considerably lower on Ta'u and Ofu and Olosega, but fishing remains an important source of food on those islands. A recent study estimated that $1,400 \mathrm{~kg}$ of fish (excluding scad) and invertebrates were harvested annually per $\mathrm{km}$ of shoreline at Ofu and Olosega [23]. Therefore, Tutuila, Ta'u, and Ofu and Olosega were classified as "populated." Rose Atoll is $130 \mathrm{~km}$ east of Ta'u and has been a FWS NWR since 1973. In 2009, waters around Rose were designated as the Rose Atoll Marine National Monument (RAMNM). Swains Island, which is part of the Tokelau chain, is located approximately $300 \mathrm{~km}$ north of the populated Samoan Islands. It is a private island inhabited by a small number of resident caretakers: 37 people in 2000 (Table 1), but population levels since then have dwindled to fewer than ten. Given their zero or low population densities, and remoteness from significant human population centers, both Swains and Rose were classified as remote.

2.2. Survey Design and Methodology. Fish data come by means of visual surveys conducted on SCUBA. Survey design and sampling domain were identical at all locations, but two visual surveys methods were used. In the Mariana Archipelago, American Samoa, and PRIA, surveys were conducted using stationary point counts (SPCs), but surveys in the Hawaiian Archipelago were conducted using belt transects. Details of those methods are given below. Pacific RAMP now uses only SPC but transition to that method had not yet occurred at the time of the Hawaii surveys. As part of that methods transition, 332 paired surveys were conducted (sites where both belt transect and SPC surveys were carried out), and those were distributed across all survey regions. Analysis of that data indicates that the two methods give very similar estimates of total biomass and planktivores biomass (mean difference between methods $<5 \%$ ) but that relative to SPC, belt transects tend to underrepresent piscivore biomass (23\% lower in belts) and overrepresent herbivore 
Table 1: Study Areas, Regions, and Status. MNM: Marine National Monument. NWR: US Fish and Wildlife Service National Wildlife Refuge. Shaded areas are those classified as remote. $N$ : no. of sites surveyed.

\begin{tabular}{|c|c|c|c|c|c|c|c|c|}
\hline Reef-area & $N$ & Lat & Long & Human Pop ${ }^{1}$ & Area of $\operatorname{Reef}^{2}\left(\mathrm{~km}^{2}\right)$ & Pop/km² Reef & $P / R$ & Notes \\
\hline \multicolumn{9}{|c|}{ Hawaiian archipelago } \\
\hline Kure & 13 & -178.33 & 28.42 & 0 & 90.2 & 0 & $R$ & \multirow{7}{*}{$\begin{array}{l}\text { Papahānaumokuākea MNM } \\
\text { established 06/2006 } \\
\text { From 09/2005 NWHI Marine } \\
\text { Refuge (state of Hawaii) banned } \\
\text { extraction of reef fishes except by } \\
\text { permit (mostly for research) at all } \\
\text { islands other than Midway. Midway } \\
\text { a NWR since } 1988\end{array}$} \\
\hline Midway & 8 & -177.38 & 28.23 & $\sim 60$ & 85.4 & $\sim 0.7$ & $R$ & \\
\hline Pearl \& Hermes & 20 & -175.85 & 27.86 & 0 & 374.5 & 0 & $R$ & \\
\hline Lisianski & 14 & -173.95 & 26.01 & 0 & 215.6 & 0 & $R$ & \\
\hline Laysan & 11 & -171.73 & 25.78 & 0 & 26.4 & 0 & $R$ & \\
\hline Maro & 12 & -170.58 & 25.41 & 0 & 217.5 & 0 & $R$ & \\
\hline French Frigate & 12 & -166.21 & 23.79 & 0 & 469.4 & 0 & $R$ & \\
\hline Kauai & 24 & -159.57 & 22.09 & 58,303 & 178.8 & 326.1 & $P$ & \\
\hline Niihau-Lehua & 20 & -160.15 & 21.90 & 160 & 6.7 & 23.9 & $P$ & \\
\hline Oahu & 14 & -158.00 & 21.49 & 876,151 & 374.8 & $2,337.6$ & $P$ & \\
\hline Molokai & 16 & -157.09 & 21.14 & 7,404 & 161.6 & 45.8 & $P$ & \\
\hline Lanai & 16 & -156.92 & 20.82 & 3,193 & 46.3 & 69.0 & $P$ & \\
\hline Maui & 34 & -156.40 & 20.82 & 117,644 & 164.6 & 714.7 & $P$ & \\
\hline Hawaii & 62 & -155.42 & 19.53 & 148,677 & 193.7 & 767.6 & $P$ & \\
\hline \multicolumn{9}{|c|}{ Mariana archipelago } \\
\hline Farallon de Pajaros & 7 & 144.89 & 20.55 & 0 & 0.8 & 0 & $R$ & \multirow{3}{*}{$\begin{array}{l}\text { Mariana Trench MNM, containing } \\
\text { Asuncion, Maug, and Farallon de } \\
\text { Pajaros, established 01/2009 }\end{array}$} \\
\hline Maug & 21 & 145.22 & 20.02 & 0 & 2.1 & 0 & $R$ & \\
\hline Asuncion & 13 & 145.40 & 19.69 & 0 & 0.5 & 0 & $R$ & \\
\hline Agrihan & 14 & 145.66 & 18.76 & 0 & 8.6 & 0 & $R$ & \multirow{5}{*}{$\begin{array}{l}\text { Several were populated prior to } \\
\text { volcanic activity in recent past (e.g., } \\
\text { at Pagan in 1981). Alamagan } \\
\text { population low but variable in } \\
\text { recent years }\end{array}$} \\
\hline Pagan & 21 & 145.76 & 18.11 & 0 & 11.1 & 0 & $R$ & \\
\hline Alamagan & 6 & 145.83 & 17.60 & 6 & 3.2 & 1.9 & $R$ & \\
\hline Guguan & 6 & 145.84 & 17.31 & 0 & 1.1 & 0 & $R$ & \\
\hline Sarigan & 7 & 145.78 & 16.71 & 0 & 1.9 & 0 & $R$ & \\
\hline Saipan & 22 & 145.75 & 15.19 & 62,392 & 56.8 & $1,098.5$ & $P$ & \\
\hline Tinian & 14 & 145.63 & 14.99 & 3,540 & 14.7 & 240.7 & $P$ & \\
\hline Aguijan & 6 & 145.55 & 14.85 & 0 & 2.6 & 0 & $P$ & \\
\hline Rota & 14 & 145.21 & 14.16 & 3,283 & 12.1 & 271.3 & $P$ & \\
\hline Guam & 25 & 144.79 & 13.46 & 154,805 & 91.3 & $1,695.6$ & $P$ & \\
\hline \multicolumn{9}{|c|}{ Pacific remote island areas (PRIA)—all within PRIA MNM (established 01/2009) } \\
\hline Wake & 29 & 166.62 & 19.30 & $\sim 100$ & 22.9 & $\sim 4.4$ & $R$ & US Air Force base \\
\hline Johnston & 11 & -169.52 & 16.74 & 0 & 150.1 & 0 & $R$ & Marine waters in NWR since 2004 \\
\hline Kingman & 26 & -162.38 & 6.40 & 0 & 20.9 & 0 & $R$ & \multirow{2}{*}{$\begin{array}{l}\text { NWR Jan } 2001 \text { to } 12 \text { nautical miles } \\
(\mathrm{nm})\end{array}$} \\
\hline Palmyra & 66 & -162.10 & 5.54 & $\sim 10-20$ & 47.2 & $0.2-0.4$ & $R$ & \\
\hline Howland & 26 & -176.62 & 0.80 & 0 & 3.0 & 0 & $R$ & \multirow{3}{*}{ NWR 1974 -to $3 \mathrm{~nm}$} \\
\hline Baker & 25 & -176.48 & 0.20 & 0 & 5.2 & 0 & $R$ & \\
\hline Jarvis & 49 & -160.00 & -0.37 & 0 & 3.0 & 0 & $R$ & \\
\hline \multicolumn{9}{|c|}{ American Samoa } \\
\hline Swains & 41 & -171.08 & -11.06 & 37 & 2.4 & 15.4 & $R$ & Human pop $\sim 10$ in recent years \\
\hline Ofu \& Olosega & 43 & -169.65 & -14.17 & 505 & 3.6 & 140.3 & $P$ & \\
\hline Tau & 36 & -169.47 & -14.24 & 380 & 3.8 & 100.0 & $P$ & \\
\hline Tutuila & 171 & -170.70 & -14.30 & 55,876 & 35.8 & $1,560.8$ & $P$ & \\
\hline Rose & 46 & -168.16 & -14.55 & 0 & 7.9 & 0 & $R$ & $\begin{array}{l}\text { RA MNM est. 01/09. NWR since } \\
1973\end{array}$ \\
\hline
\end{tabular}

Notes. (1) Population data from US Census 2000 (http://www.census.gov/main/www/cen2000.html) [21]; (2) area from shoreline to 10 fathom line [24]. 


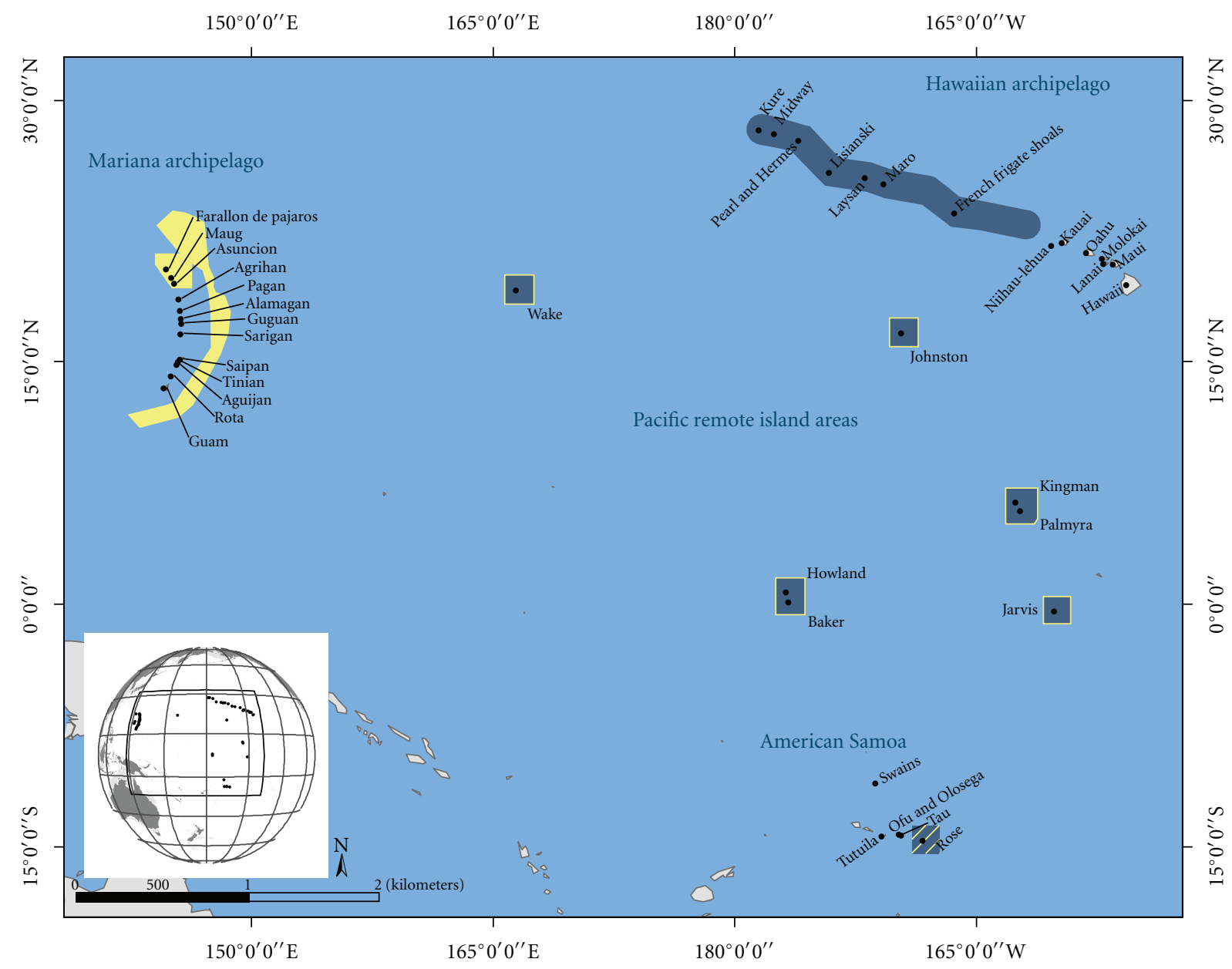

National marine monument boundary

Mariana trench
Pacific remote island $\quad \square$ Rose atoll
—ahānaumokuākea

FIgURE 1: Locations of the reef-areas (i.e., islands and atolls) surveyed by NOAA CRED for Pacific RAMP between 2008 and April 2010. Boundaries of US Pacific Marine National Monuments are indicated. Note that labels are only shown for reef-areas that were surveyed by the Pacific RAMP in that period. The number of sites surveyed per reef-area is given in Table 1.

and secondary consumer biomass (by 19\% and 34\%, resp., CRED unpublished data).

The SPC protocol closely follows that used by Ault and colleagues [25], and involved a pair of divers conducting simultaneous counts in adjacent visually estimated $15 \mathrm{~m}$ diameter plots extending from the substrate to the limits of vertical visibility. Prior to beginning each SPC pair, a 30 $\mathrm{m}$ line was laid across the substratum. Markings at $7.5 \mathrm{~m}$, $15 \mathrm{~m}$, and $22.5 \mathrm{~m}$ enabled survey divers to locate the mid point $(7.5 \mathrm{~m}$ or $22.5 \mathrm{~m})$ and two edges $(0 \mathrm{~m}$ and $15 \mathrm{~m}$; or $15 \mathrm{~m}$ and $30 \mathrm{~m}$ ) of their survey plots. Each count consisted of two components. The first of those was a 5-minute species enumeration period in which the diver recorded all species observed within their cylinder. Following that was the tallying portion, in which the diver systematically worked through their species list successively recording the number and size (total length, TL, to nearest $\mathrm{cm}$ ) of all fishes on the species list. The tallying portions were conducted as a series of rapid visual sweeps of the plot, with one species grouping counted per sweep. To the extent possible, divers remained at the center of their cylinders throughout the count. However, small and cryptic species, which will tend to be underrepresented in counts made by an observer remaining in the center of a $7.5 \mathrm{~m}$ radius cylinder, were left to the end of the tally period, at which time the observer swam through their plot area carefully searching for those species. In cases where a species was observed during the enumeration period but was not present in the cylinder during the tallying period, divers recorded their best estimates of size and number observed in the first encounter during the enumeration period and marked the data record as "noninstantaneous." Surveys were not 
conducted if horizontal visibility was $<7.5 \mathrm{~m}$; that is, when observers could not distinguish the edge points of their cylinder.

For belt transect surveys, a pair of divers swam in parallel recording the species, number, and size (TL to nearest $\mathrm{cm}$ ) of all fishes encountered on replicate $25 \mathrm{~m}$ long belt transects per site. Each transect was surveyed on two passes: an outward swim in which observers counted fishes $\geq 20 \mathrm{~cm}$ on adjacent nonoverlapping $4 \mathrm{~m}$-wide belts (total transect width for the survey pair of $8 \mathrm{~m}$ ) and a return swim in which fishes $<20 \mathrm{~cm}$ were counted on $2 \mathrm{~m}$ wide belts (total transect width for survey pair on return swim of $4 \mathrm{~m}$ ). Transects extended upwards to limits of vertical visibility.

2.3. Data Handling and Analysis. Replicate SPC and belttransect counts were always pooled at the site level prior to analysis (i.e., to the mean of the replicate belt transects or SPCs conducted at a site by a dive team in a single dive). The core measure used for this study was estimated mass of fishes per unit area (hereafter "biomass"). Mass of individual fishes was calculated using length to weight (LW) conversion parameters, and, where necessary, length-length (LL) parameters (for example, to convert TL to fork length [FL] for species with LW parameters based on FL). LW and LL conversion parameters were taken from a range of published and web-based sources [26, 27].

Species data were pooled into "all fishes," and into a number of trophic, taxonomic, and size groupings. The four trophic groupings used were "primary consumers" (herbivores and detritivores); "secondary consumers" (omnivores and benthic invertivores); "planktivores;" and "piscivores," (see http://escholarship.org/uc/item/5394f7m3 for species classifications), based on diet information taken largely from FishBase [26].

It was not possible to perform meaningful species level analyses because study locations are spread across a range of biogeographic regions, and because, even within regions, few species were encountered frequently enough to be analyzed at that level. Therefore, the taxonomic groupings used were based largely on family, while taking account of trophic group and body size. For example, Serranidae includes both "groupers" (medium to large-bodied ambush predators that are often fishery targets) and also anthias (small-bodied and generally schooling planktivores that are rarely fished in most locations) [28]. Similarly, Carangidae include large-bodied taxa such as Caranx ignobilis and Seriola dumerili as well as smaller-bodied schooling planktivorous scad (Decapterus spp., Atule mate, and Selar crumenophthalmus). Therefore, the main jack group analyzed was "nonplanktivorous jacks" (i.e., all species other than scad), which seems a more appropriate functional grouping than "all jacks." Additionally, excluding such heavily clumped highly mobile and rarely encountered taxa will tend to improve data quality, as biomass of those are likely to be poorly estimated by visual surveys of small-area plots, such as were used for this study.

Taxonomic groupings considered to be commonly targeted by fishers or vulnerable to fishery depletion were (i) reef sharks (Carcharhinidae and Ginglymostomatidae); (ii) jacks (Carangidae) excluding planktivores; (iii) parrotfishes (Scaridae); (iv) groupers (Serranidae excluding Anthiinae); (v) snappers (Lutjanidae); (vi) emperors (Lethrinidae); (vii) surgeonfishes (Acanthuridae); (viii) goatfishes (Mullidae). Three species of introduced fish (two snapper: Lutjanus kasmira, L. fulvus, one grouper: Cephalopholis argus) were excluded from Hawaiian target fish groups. Hawaii has few native grouper or snapper species, which led to their deliberate introduction by the state government in the 1950s in the hope of developing new fisheries [29]. To date, they have not become preferred target species and in fact are often considered to be pests by local fishers [29]. In addition, the within archipelagic distributions of those species are likely still influenced by the fact that founder populations were released in the main islands. For example, although Cephalopholis argus is abundant in several places in the MHI, only four individuals have been recorded during Pacific RAMP belt surveys in the NWHI since the program began in 2000, and those were all at the most southerly reef areas of the NWHI chain.

Fishes were also pooled into six taxonomic groupings which were considered to be lightly or negligibly fished across the majority of reef areas in this study: (i)angelfishes (Pomacanthidae); (ii) nonplanktivorous butterflyfishes (Chaetodontidae), that is, all species other than Hemitaurichthys spp., Chaetodon kleinii, Chaetodon miliaris, and Heniochus spp.; (iii) small wrasses (Labridae), being all species with maximum length $<20 \mathrm{~cm}$; (iv) small hawkfishes (Cirrhitidae), as above limited to species with maximum length $<20 \mathrm{~cm}$; (vi) planktivorous damselfishes; (vi) all other damselfishes. Hawkfish and wrasse species with maximum length $>20 \mathrm{~cm}$ TL were excluded from these nontarget groupings because larger-bodied taxa such as Bodianus spp., Cheilinus undulatus, and Cirrhitus pinnulatus are targeted in some locations. A size-based threshold was used because, given the spatial scale of this study, it was not possible for us to make reliable judgments regarding the fishery desirability of all species at each location. Small hawkfishes and wrasses, as defined here, made up $86 \%$ and $65 \%$, respectively, of counts of fishes in those families.

Finally, as it is widely recognized that large-bodied species and large individuals tend to be preferentially targeted by reef fisheries [10, 30, 31], remote-populated differences among different size classes were explored, with fishes pooled into six size-based categories: TL $<10 \mathrm{~cm} ; 11-$ $20 \mathrm{~cm} ; 21-30 \mathrm{~cm} ; 31-40 \mathrm{~cm} ; 41-50 \mathrm{~cm} ;>50 \mathrm{~cm}$.

Pacific-wide comparisons of mean fish biomass between the 15 reef-areas classified as "populated" and the 24 classified as "remote" were made using Wilcoxon tests [32].

\subsection{Quantifying Differences between Remote and Populated} Portions of Each Archipelago. As described above, all the PRIA were classified as "remote." The three other island groups, the Mariana and Hawaiian Archipelagos and American Samoa, contained both "remote" and "populated" subregions. For these three islands groups, the primary goal of the analysis was to quantify the extent of differences in biomass between the 'remote' and "populated" subregions for the fish 
groupings described above. More details of the analytical methods are given below, but, in brief, the mean difference in biomass between remote and populated subgroups within an archipelago was calculated, and a bootstrapping approach was used to estimate $2.5 \%$ and $97.5 \%$ quantiles (i.e., a range covering the middle $95 \%$ of the distribution $=95 \%$ quantile range $[95 \% \mathrm{QR}]$ ) of those differences. Differences were normalized by dividing by mean biomass of populated reef areas to generate biomass ratios (BRs). $95 \% \mathrm{QR}$ of a biomass ratio not overlapping 1 was interpreted as being evidence of difference between archipelagic subregions, with $95 \% \mathrm{QR}>1$ indicating higher biomass at remote reef areas, and $95 \% \mathrm{QR}<1$ as evidence of lower biomass at remote areas.

For parametric data, it is relatively easy to calculate means and confidence intervals of differences between data sets. However, as is not uncommon for coral reef fish visual survey data, biomass densities of several fish groups of interest were highly nonnormally distributed both within reef areas and within archipelagos. Transforming the data to make it conform to the requirements of parametric analyses was not attempted because of the difficulty in meaningfully interpreting backtransformed biomass ratios. Therefore, in order to apply a consistent analytical approach across all groupings, a bootstrapping method was used to calculate distributions of biomass ratios. Bootstrapping involves repeated resampling with replacement from an existing data set, in this case, from the biomass densities of all sites at a reef area, to generate pseudo samples of the same size as the original data set [33]. Multiple such bootstrap samples provide the basis for calculating distribution statistics that are based on the actual distribution of the survey data, rather than having to rely on assumptions about the form of that distribution (e.g., that data are normally distributed). To illustrate this, for an archipelago with $m$ reef areas there were $m$ data setsone for each reef area, each set being a random sample consisting of all site surveys at that reef area. For example, in the Hawaiian Archipelago there were 15 reef areas: eight classified as populated and seven as remote. Among those reef areas, sample sizes ranged from 8 to 62 (Table 1). For a reef-area $i$ with $n$ survey-sites, the original data set can be represented as $X^{i}=\left(x_{1}^{i}, x_{2}^{i}, x_{3}^{i}, \ldots, x_{n}^{i}\right)$. Random resampling of that data set with replacement gives a bootstrap sample also of length $n: X^{i *}=\left(x_{1}^{i *}, x_{2}^{i *}, x_{3}^{i *}, \ldots, x_{n}^{i *}\right)$, with mean of $\overline{x^{i *}}$. Doing that for all reef areas within an archipelago gives bootstrap sample means for the $m$ reef-areas of $\overline{x^{1 *}}$ to $\overline{x^{m *}}$. Averaging the bootstrap sample means separately for remote and populated areas gives bootstrap means for the remote and populated portions of the archipelago. By repeating that process 10,000 times per archipelago and fish group of interest, we were able to generate the $2.5 \%$ and $97.5 \%$ quantiles of the distributions of differences in biomass between subregions. Analyses were performed using the $\mathrm{R}$ statistical program version 2.9.2 (R Development Core Team, http://www.r-project.org).

\section{Results}

3.1. Pacific Wide. Among the 39 reef areas, estimated mean total fish biomass ranged from $<20 \mathrm{~g} \mathrm{~m}^{-2}$ at the heavily populated islands of Guam, Saipan, and Tinian (mean \pm SE: $13.2 \pm 1.5 \mathrm{~g} \mathrm{~m}^{-2}, 18.2 \pm 1.7,18.9 \pm 1.5 \mathrm{~g} \mathrm{~m}^{-2}$, resp.) to around $250 \mathrm{~g} \mathrm{~m}^{-2}$ and above at the unpopulated and extremely isolated reef areas of Jarvis and Kingman in the PRIA $\left(246.8 \pm 36.9,296.2 \pm 40.5 \mathrm{~g} \mathrm{~m}^{-2}\right)$ and Kure in the NWHI $\left(347.9 \pm 212.7 \mathrm{~g} \mathrm{~m}^{-2}\right.$, Figure 2$)$.

While there was considerable variability among reef areas within the "remote" and "populated" classifications and among archipelagos, there was a clear tendency at both Pacific-wide and archipelagic scales for biomass to be higher at remote reef areas (Figure 2). At the Pacific-wide scale, the grand mean of estimated total biomass for the 15 populated reef areas $\left(33.2 \pm 3.4 \mathrm{~g} \mathrm{~m}^{-2}\right)$ was less than a quarter of that for the 24 remote reef areas $\left(131.1 \pm 16.3 \mathrm{~g} \mathrm{~m}^{-2}\right)$. Additionally, the highest biomass at any populated reef area, $59.2 \pm$ $6.8 \mathrm{~g} \mathrm{~m}^{-2}$ at Niihau-Lehua, was less than half of the grand mean of remote areas. In stark contrast to the populated reef areas, 15 of 24 remote reef areas had mean total fish biomass $>100 \mathrm{~g} \mathrm{~m}^{-2}$ (Figure 2).

At Pacific-wide scale, remote areas tended to have higher biomass in all trophic groups (Wilcoxon test $P<.05$ in all cases), but the scale of difference was greatest for piscivores (Figure 2). The estimated mean piscivore biomass at remote reef areas ranged from $9.4 \mathrm{~g} \mathrm{~m}^{-2}$ at Maug to $231.6 \mathrm{~g} \mathrm{~m}^{-2}$ at Kure (grand mean $=59.7 \mathrm{~g} \mathrm{~m}^{-2}$ ), whereas at populated reef areas it varied from $0.8 \mathrm{~g} \mathrm{~m}^{-2}$ at Oahu to $9.8 \mathrm{~g} \mathrm{~m}^{-2}$ at Aguijan (grand mean $=4.2 \mathrm{~g} \mathrm{~m}^{-2}$ ). Piscivores made up between $9 \%$ and $68 \%$ of the total estimated biomass at remote areas (grand mean $=40 \%$ ) and were the largest component of total biomass at half of the remote reef areas (Figure 2). In contrast, piscivores were a small portion of total biomass at nearly all populated reef areas (grand mean $=13 \%$; and $18 \%$ or less everywhere other than Aguijan where they made up $38 \%$ ) and comprised as little as $3 \%$ of total fish biomass at $\mathrm{Oahu}$, the most densely populated island in this study. At all 15 of the populated areas primary consumers (88\% made up of surgeonfishes and parrotfishes) were the largest component of biomass ( 38 to $54 \%$, grand mean $=50 \%$, Figure 2).

3.2. Hawaiian Archipelago. Within the Hawaiian Archipelago, total fish biomass at remote reef areas was over four times that at populated islands (BR: 4.5, 95\%QR: 3.36.3, Figure 3). Remote reef-areas had higher biomass in all trophic groups (i.e., BR $>1$ and $95 \% \mathrm{QR}$ did not overlap $1)$, but the scale of differences was considerably larger for piscivores (BR: 22.1, 10.3-44.2), than for other trophic groups, which had biomass ratios between two and three (primary consumer BR: 3.0, 2.5-3.6; secondary consumer BR: 2.1, 1.7-2.8, planktivore BR: 2.6, 1.7-3.5).

Biomass of all target groups was higher at remote Hawaiian reef areas than at populated areas (Figure 3). The largest such differences were for sharks and large jacks, which had biomass ratios $>50$ (shark BR: 50.9, 16.3-101.0; jack BR: 131.5, 49.2-291.1), and for emperors (BR: 13.4, 4.1-29.6). Remote area biomass of parrotfishes and native snappers was, respectively, $3.6(2.9-4.3)$ and $4.2(2.7-5.7)$ times that at populated reef areas. Among target groups, the smallest 


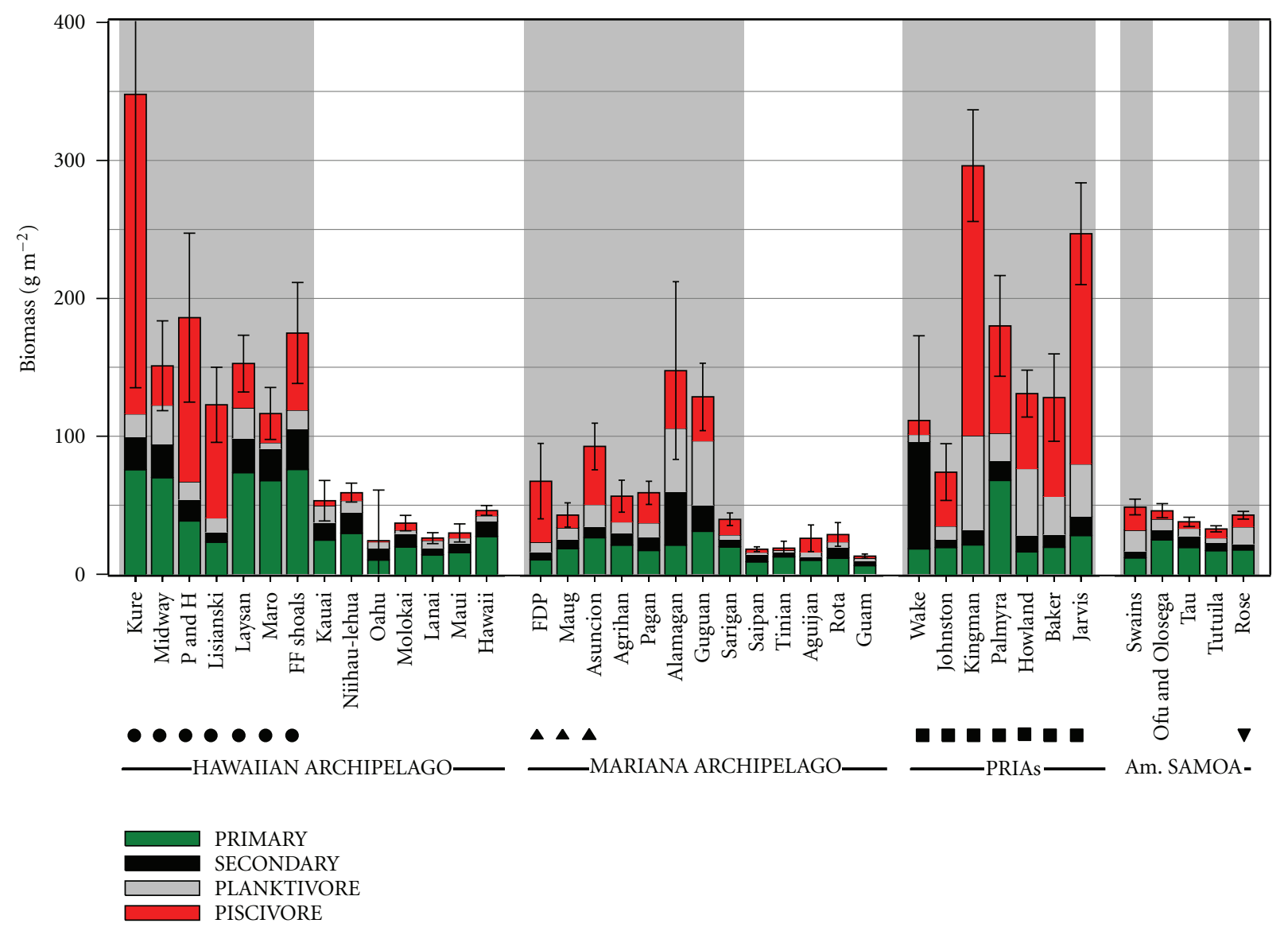

FIGURE 2: Mean biomass per reef-area by trophic grouping. Vertical bars indicate \pm 1 SE (for total biomass) with all fore reef sites per location as replicates. Reef-areas are grouped by region (Hawaiian and Mariana Archipelagos, PRIA, American Samoa). Within regions, reef-areas are ordered by latitude with most northerly reef-areas to the left. Shaded portions of the figures indicate "remote" reef-areas, as defined in Section 2. Reef-areas within Marine National Monuments (MNMs) are identified by circles for Papahānaumokuākea MNM; upright triangles for Mariana Trench MNM; squares for Pacific Remote Islands MNM; and inverted triangle for Rose Atoll MNM.

biomass ratios were for surgeonfishes $(1.9,1.5-2.3)$ and goatfishes $(1.6,1.03-2.2)$. Native groupers were not recorded at any Hawaiian Archipelago site during the survey period.

Nontarget groups also tended to have higher biomass at remote reef-areas than at populated areas within the Hawaiian Archipelago, but in no case was that difference as large as it was for some of the target groups (Figure 3). For three of the six nontarget groups there was either no clear difference between remote and populated reef areas (95\%QRs for nonplanktivorous butterflyfishes and small hawkfishes overlapped one) or the difference was marginal (small wrasse BR: 1.4, 1.1-1.7). However, for three of six nontarget taxa, biomass at remote reef areas was between three and nearly five times that at populated reef areas: angelfish (BR 4.1, 2.9-5.6); benthic damselfishes (BR: 3.3, 2.7-4.1); planktivorous damselfishes (BR:4.6, 3.1-6.6).

For all size classes, biomass was higher at remote reef areas (Figure 3). The lowest biomass ratios, ranging from 1.7 to 3.3 , were for the smallest size classes (i.e., fishes $<31 \mathrm{~cm}$, Figure 3). For the largest size classes, $41-50 \mathrm{~cm}$ and $>50 \mathrm{~cm}$, biomass ratios were, respectively, $7.5(5.4-10.9)$ and 16.5 (8.0-31.5).
3.3. Mariana Archipelago. As with the Hawaiian Archipelago, remote Mariana reef-areas had total fish biomass around four times that of populated reefs (BR 3.8, 3.0-4.7, Figure 3). Mariana remote areas also had higher biomass than populated reef-areas for all trophic groups (Figure 3), with substantial differences for piscivores (BR: 6.8, 4.8-9.2) and planktivores (BR: 6.8, 4.4-9.5) but relatively small differences for primary and secondary consumers, which had biomass ratios of between two and three (primary consumer BR: 2.1, 1.7-2.4; secondary consumer BR: 2.8, 1.7-4.5).

Within the Mariana Archipelago, seven of eight target groupings had higher biomass at remote reef-areas than at populated reef-areas (Figure 3 ). The one exception was emperors, for which high variability among samples and reef-areas contributed to a wide range of bootstrap differences between remote and populated areas. Hence, although BR was 2.5, the 95\%QR (0.9-3.7) overlapped one. Among target groups with highest biomass ratios were snappers (BR: 18.0, 11.7-26.6) and jacks (BR: 14.5, 8.6-22.8). Biomass of sharks and grouper was also considerably higher at remote reef-areas, being more than four times that observed at populated islands within the chain (shark BR: BR 4.1, 


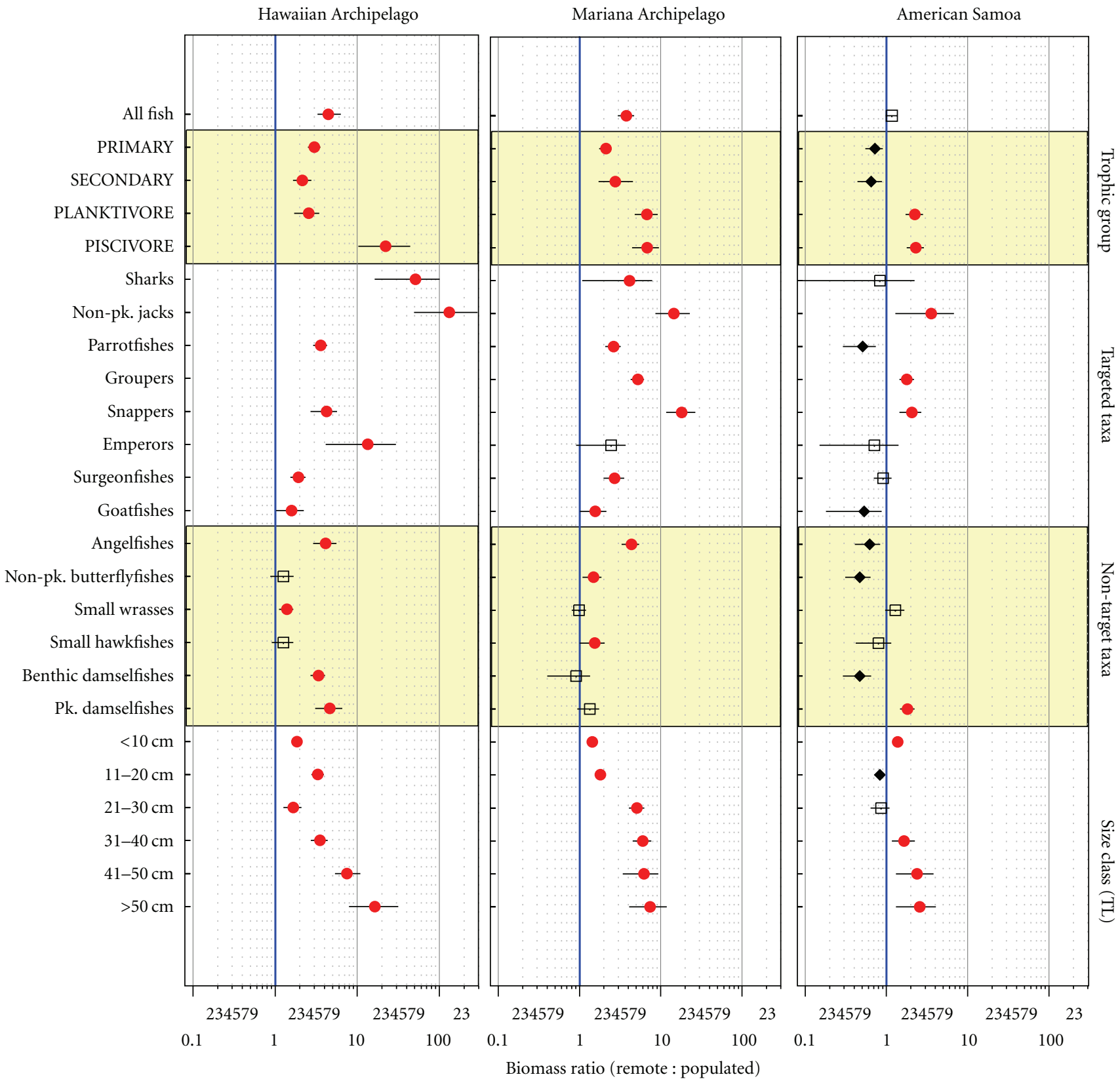

FIGURE 3: Differences in reef fish assemblages between remote and populated portions of US Pacific coral reef regions. Differences are given as the ratio of biomass between remote and human-populated portions of each region. The blue vertical line represents a ratio of one (i.e., no difference in biomass between remote and populated reef-areas). Horizontal bars indicate 95\% quantile-range. Red circles: higher biomass at remote reef-areas; that is, positive biomass ratio and 95\% quantile-range do not overlap one. Black diamonds: lower biomass at remote reef-areas; that is, ratio is negative and quantile-range does not overlap one. Open squares: $95 \%$ quantile-range overlaps one. Details of the analysis are given in Section 2.

1.1-7.8; grouper BR: 5.2, 4.3-6.2). While less substantial, biomass ratios of $2.7(2.0-3.6)$ for surgeonfishes and 2.6 (2.1-3.2) for parrotfishes represent nontrivial differences, as even the low bound of the $95 \%$ QRs indicate greater than twice the biomass at remote reef-areas. As in the Hawaiian Archipelago, goatfishes had the lowest biomass ratio among target groups (BR: 1.6, 1.01-2.1).
Only one of the six nontarget groups, angelfishes, had substantially higher biomass at remote Mariana reef-areas than at populated areas (BR: 4.3, 3.3-5.4). For the other five nontarget groups there were either no clear differences between remote and populated reef-areas (i.e., 95\%QRs overlap one, which was the case for small wrasses, and both damselfish groupings, Figure 3), or biomass was marginally 
higher at remote areas (nonplanktivorous butterflyfishes BR: 1.5, 1.1-1.9; small hawkfishes BR: 1.5, 1.004-2.0).

As in the Hawaiian Archipelago, fish biomass was higher at remote areas in all size classes and remote-populated differences were much greater for the larger size classes (Figure 3), which had biomass six or more times that at populated areas (e.g., $41-50 \mathrm{~cm}$ BR: $6.2,3.4-9.3 ;>50 \mathrm{~cm}$ BR: 7.4, 4.1-11.8), than for the smaller size classes $(1-10 \mathrm{~cm} \mathrm{BR:}$ 1.4, 0.2-1.8; 11-20 cm BR: 1.8, 1.5-2.0).

3.4. American Samoa. Unlike the Mariana and Hawaiian Archipelagos, differences between the remote and populated reef-areas of American Samoa were less distinct. Neither of the two remote American Samoan reef-areas (the highest biomass of which was $48.8 \pm 5.8 \mathrm{~g} \mathrm{~m}^{-2}$ at Swains) had total fish biomass comparable to values found at remote reefareas in other archipelagos (Figure 2). Overall, at American Samoa, there was no difference in total fish biomass between remote and populated reef-areas (BR: 1.2, 0.98-1.4). The two remote reef-areas had lower biomass of primary and secondary consumers than the three populated reef-areas (primary BR: 0.7, 0.6-0.9; secondary consumer BR: 0.6, 0.40.9 ), but higher biomass of planktivores (BR: 2.2, 1.7-2.8) and piscivores (BR: 2.3, 1.8-2.9).

Although target fish biomass was not consistently greater at remote reef-areas of American Samoa: there were clear differences for 5 of the 8 target fish groups: biomass of jacks, snappers, and groupers was higher at remote areas (BRs: 3.5, 1.3-6.8; 2.1 1.5-2.7; and 1.8, 1.4-2.2); but remote areas biomass of parrotfish and goatfish was around half that at populated areas (BRs: 0.5, 0.3-0.7; and 0.5, 0.20.9 , resp., Figure 3). There were no clear differences for emperors, surgeonfishes, or sharks (Figure 3). Similarly, among nontarget taxa, biomass of two of six groupssmall wrasses and small hawkfishes-did not clearly differ between remote and populated reef-areas (Figure 3). However, remote areas had lower biomass of angelfishes, nonplanktivorous butterflyfishes, and benthic damselfishes (BRs: $0.6,0.4-0.8 ; 0.5,0.3-0.6$; and $0.5,0.3-0.6$, resp.), and slightly higher biomass of planktivorous damselfishes (BR: $1.8,1.5-2.2$ ).

As at other island groups, biomass differences between remote and populated areas were least for the smaller size classes, but increased as size class increased, with both 41-50 $\mathrm{cm}$ and $>50 \mathrm{~cm}$ size classes having biomass ratios of greater than 2 (41-50 cm BR: 2.4, 1.3-3.8; >50 cm BR: 2.6, 1.3-4.1).

\section{Discussion}

The 39 islands and atolls included in this study span wide ranges both geographically and in terms of potential human impact, from the heavily populated, urbanized, and physically altered islands of Oahu and Guam to the isolated reefareas of Jarvis, Baker, and Howland, which are several hundred kilometers from the nearest human settlement. Clearly there are substantial physical, biological, and oceanographic differences among surveyed areas which likely influence standing biomass and structure of reef fish assemblages
[34-38], and therefore limit the ability to draw definitive conclusions about the importance of single factors such as the presence of local human populations. Nevertheless, whatever the causes, this study robustly quantifies the extent of differences in reef fish assemblages between populated and remote reef-areas, and demonstrates the generality of those differences across large portions of the central and western Pacific. Such differences are clearly ecologically significant remote reef-areas having, on average, fish biomass around four times that found at populated areas. The magnitude of the differences between remote and populated islands was consistent with earlier smaller-scale studies of isolated reefs in the Pacific $[1,2,4]$. Also in common with those studies, the most striking difference we observed between remote and populated reefs was that large-bodied piscivores, such as sharks and jacks, were a conspicuous presence and made up a substantial portion of survey biomass at many of the remote reef-areas, but were rarely encountered around populated islands. For example, sharks were recorded during 101 of the 231 surveys in the PRIA, but on only two of 232 surveys at the four most densely populated islands: Oahu, Guam, Saipan, and Tutuila.

Because biogeographic differences among regions, such as low diversity of native groupers, snappers, and emperors on Hawaiian reefs, have the potential to confound Pacificwide comparisons, we focused on within-archipelagic comparisons for the three island groups containing both remote and populated reef-areas: Hawaiian, Mariana, and American Samoa. At two of those-Hawaiian and Mariana-there were distinct and consistent differences between remote and populated reef-areas, with nearly all (21 and 19, resp.) of the 23 fish groupings having higher biomass at remote reef-areas, and no grouping having higher biomass around populated areas. The patterns of difference between remote and populated reefs within those archipelagos were similar to those at the Pacific-wide scale: total biomass at remote reefs was $\sim 4$ times that at populated reef-areas, and remote biomass was higher in all trophic groups but particularly so for piscivores (biomass ratios of $\sim 22$ and $\sim 7$, resp.). However, differences between remote and populated reefareas in American Samoa were more complex: biomass of ten groups was higher at remote areas, but seven groups had lower biomass at remote reef-areas. This may reflect fundamental differences in oceanography, in types of human impact, or in ecological resilience at American Samoa. However, it seems more likely that it was due to a combination of (1) limited numbers of surveyed islands and atolls in American Samoa (only 5 in total: 2 nominally remote, 3 populated, compared to the 13 reef-areas in both Mariana and Hawaii chains, with 5-8 in each of remote and populated); (2) less distinct difference between the areas classified as remote and populated in American Samoa than within other archipelagos. Mariana and Hawaiian remote islands were nearly all uninhabited and distant from the nearest human population center (in the case of the NWHI, all were $>600 \mathrm{~km}$ from the nearest population center). In contrast, of the two remote American Samoa areas, Rose Atoll is $\sim 130 \mathrm{~km}$ from the populated Manu'a Islands, and the other, Swains Island, has a small resident population. 
Also, both Rose and Swains have relatively small shallow nearshore habitats ( 7.9 and $2.4 \mathrm{~km}^{2}$, resp., Table 1$)$, so even low absolute levels of human activity have the potential to have tangible impacts there.

While we do not discount the importance of other anthropogenic impacts on habitat or environmental quality $[17,39]$, there is abundant evidence that increased fishing pressure is normally one of the main reasons for the depletion of coral reef fish populations, particularly of preferred target species, around populated areas, or in comparison to marine reserves that have had effective longterm protection $[5,8,10-12,40,41]$. Results from this study are consistent with fishing being among the main drivers of difference between remote and populated areas, particularly within the Hawaiian and Mariana Archipelagos. First, remote areas had higher biomass of virtually all target groups in those archipelagos, but for nontarget groups the remote-populated differences were mixed. Emperors in the Mariana were the only target group which did not have clearly higher biomass in remote areas. However, a biomass ratio of 2.5 but wide quantile range indicates that the lack of statistical significance for that group was more likely a consequence of high variability than small effect size. Most other target groups had remote areas biomass that was more than double that at populated areas. In contrast, five of the six nontarget groups in the Mariana were either not significantly different or had biomass ratios of 1.5 or below; and three of the six nontarget groups in Hawaii showed no or low difference between populated and remote areas. Secondly, among target groups, the remote-populated differences were greatest for larger size classes and for taxa which tend to be most vulnerable to fishery depletion, that is, jacks, sharks, snappers, and grouper [30, 42]. Remote-populated differences were less pronounced for goatfish and surgeonfishes, that is, taxa with life history characteristics, such as rapid growth to asymptotic size and early maturity, which tend to make them relatively resilient to fishing [43-45]. Lower remote-populated biomass ratios for those groups could also reflect lower fishing pressure on those groups, or in the availability of suitable habitat. Although remote-populated differences were less clear-cut among American Samoan reefareas, remote reefs had around double or more biomass of groupers, snappers, jacks, and size classes larger than $40 \mathrm{~cm}$. Those patterns are consistent with those areas being less impacted by fishing than populated areas. However, remote-populated biomass ratios significantly different from one for multiple nontarget groups within each archipelago emphasize that fishing pressure alone does not fully explain the differences we found between remote and populated archipelagic subregions. Localized human impacts other than fishing have the potential to have large and widespread impacts [16, 17]. In addition, over the scale of entire archipelagos there are large differences in both physical and oceanographic factors, and in habitat quality and availability, which are sufficient to affect local reef fish assemblages $[20,38]$.

One obvious difficulty for any comparison of extremely remote and heavily populated coral reef-areas is that medium to large land masses tend to be populated, but very small atolls and areas with limited emergent land tend not to be. Hence, some degree of confounding between island type and population status seems unavoidable. We believe it is useful to present robust information on large-scale patterns, but clearly there is a need for more detailed analysis of fish assemblages and standing stock in relation to a range of potential human, habitat, and environmental factors, particularly if that can be done at lower taxonomic levels, which are likely to be more closely tied to forcing factors than are functional groupings [39].

As with any study using data from underwater visual surveys, the presence of divers has the potential to alter fish behavior in ways that can lead to undercounting of species that tend to avoid divers [46], particularly if fishes have learned to associate divers with fishing [47]. Overcounting of species that are attracted to divers can also occur, as seems to be the case for sharks and jacks in the NWHI [48]. In general, underwater visual survey data gathered by divers are best treated as relative rather than absolute measures of density, particularly given the scope for differences in survey methods including dimensions, observer training and experience level, and survey design to impact densities derived from underwater counts [49-53]. For this study, survey design and sampling domain were common throughout (sites were randomized within $0-30 \mathrm{~m}$ hardbottom), and there were no systematic differences in observer training level or experience between regions or subregions, as the same survey personnel tended to survey remote and populated regions within the same archipelago on a single cruise. Although we do present some results as biomass densities (e.g., as $\mathrm{g} \mathrm{m}^{-2}$ ), we focused our analytical efforts on estimating relative biomass density (i.e., biomass ratios) between remote and populated reef-areas within archipelagos (i.e., where methods were consistent throughout), and on comparisons at Pacific-wide scale, where the divergence in methodology might have contributed to perceived differences between regions but was not plausibly an important factor in the clear disparity between remote and populated reef-areas at that scale.

The binary remote/populated classification scheme used in this study was rather crude. Human population density per reef-area varied by two orders of magnitude among "populated" reef-areas (least at Niihau-Lehua and highest at Oahu), which in turn meant that there are likely to be substantial differences in human impact on local reef fish populations among those areas [8]. Similarly "remote" reef-areas included extremely isolated reef-areas as Jarvis, Kingman, Baker and the NWHI, but also areas much closer to human population centers, such as Sarigan in the Mariana and Rose Atoll in American Samoa. Both Sarigan and Rose Atoll are within $\sim 150 \mathrm{~km}$ of the nearest inhabited island, and are therefore much more accessible to and potentially impacted by human activities. Better understanding of the extent of human activities over medium to large distancesthat is, scales of several tens to hundreds of kilometerswould allow for more sophisticated classifications than the simple "remote" and "populated" scheme used here. However, it is likely to remain difficult to reliably quantify human activities, including fishing, at isolated and uninhabited reefareas, and we do not currently have the ability to make 
meaningful assessments of those at the study locations. While the simple classifications used likely underestimates the difference between the most remote and the most populated areas covered by Pacific RAMP, it was sufficient to highlight substantial differences in reef fish assemblages between those two broad categories. Notably, even with the low bar to being considered "populated" and the likelihood that some of the areas we classified as "remote" were fished to some degree, the highest reef fish biomass of the 15 populated areas, at Niihau-Lehua, was less than half of the average of all reef-areas classified as remote (and closer to a third of the average of the most isolated reefs). Although remoteness, as defined here, did not guarantee an area would support high fish biomass (e.g., six of 24 remote areas had lower mean biomass than Nihau-Lehua), the low upper limit to populated area biomass strongly suggests that even relatively low human population density and/or proximity to larger population centers is incompatible with anything resembling a pristine reef fish community structure. These results are consistent with studies showing that even low levels of exploitation can have substantial impacts on reef fish assemblages $[6,10,11]$, and reinforces the importance, as biological and ecological reference areas, of the extremely isolated coral reef-areas now contained within the system of the US Marine National Monuments.

\section{Acknowledgments}

This work was part of an interdisciplinary effort by the NOAA Pacific Islands Fisheries Science Center's Coral Reef Ecosystem Division to assess, understand, and monitor coral-reef ecosystems. Paula Ayotte, Kaylyn McCoy, Marie Ferguson, Kevin Lino, Mark Manuel, Emily Donham, Jonatha Giddens, Darla White, Valerie Brown, Paul Brown, Kosta Stamoulis, and Amanda Meyer assisted with data gathering. Tomoko Acoba generated the map given as Figure 1. The authors would also like to thank the officers and crews of the NOAA Ships Hi'ialakai and Oscar Elton Sette for logistic support and field assistance. Funding for surveys (as part of the Pacific Reef Assessment and Monitoring Program, RAMP) was provided by NOAA's Coral Reef Conservation Program. Permission to work in the NWHI was granted by the Papahānaumokuākea Marine National Monument, US Fish and Wildlife Service, Department of the Interior and the State of Hawaii Department of Land and Natural Resources. Permission to work in the Mariana Archipelago was granted by the Commonwealth of the Northern Mariana Islands (CNMI) Division of Fish and Wildlife, Coastal Resources Management Office, Division of Environmental Quality and the Guam Division of Aquatic and Wildlife. Permission to work in American Samoa was granted by the Department of Marine and Wildlife Resources. Bill Walsh, Jill Zamzow, and Fran Fuist provided very helpful comments on earlier drafts.

\section{References}

[1] A. M. Friedlander and E. E. DeMartini, "Contrasts in density, size, and biomass of reef fishes between the northwestern and the main Hawaiian islands: the effects of fishing down apex predators," Marine Ecology Progress Series, vol. 230, pp. 253264, 2002.

[2] S. A. Sandin, J. E. Smith, E. E. DeMartini et al., "Baselines and degradation of coral reefs in the Northern Line Islands," PLoS One, vol. 3, no. 2, Article ID e1548, 2008.

[3] M. J. H. Newman, G. A. Paredes, E. Sala, and J. B. C. Jackson, "Structure of Caribbean coral reef communities across a large gradient of fish biomass," Ecology Letters, vol. 9, no. 11, pp. 1216-1227, 2006.

[4] C. Stevenson, L. S. Katz, F. Micheli et al., "High apex predator biomass on remote Pacific islands," Coral Reefs, vol. 26, no. 1, pp. 47-51, 2007.

[5] C. D. Stallings, "Fishery-independent data reveal negative effect of human population density on Caribbean predatory fish communities," PLoS One, vol. 4, no. 5, Article ID e5333, 2009.

[6] J. B. C. Jackson, "Reefs since Columbus," Coral Reefs, vol. 16, no. 1, pp. S23-S32, 1997.

[7] E. E. DeMartini, A. M. Friedlander, S. A. Sandin, and E. Sala, "Differences in fish-assemblage structure between fished and unfished atolls in the northern Line Islands, central Pacific," Marine Ecology Progress Series, vol. 365, pp. 199-215, 2008.

[8] I. D. Williams, W. J. Walsh, R. E. Schroeder, A. M. Friedlander, B. L. Richards, and K. A. Stamoulis, "Assessing the importance of fishing impacts on Hawaiian coral reef fish assemblages along regional-scale human population gradients," Environmental Conservation, vol. 35, no. 3, pp. 261-272, 2008.

[9] N. A. J. Graham, R. D. Evans, and G. R. Russ, "The effects of marine reserve protection on the trophic relationships of reef fishes on the Great Barrier Reef," Environmental Conservation, vol. 30, no. 2, pp. 200-208, 2003.

[10] N. K. Dulvy, N. V. C. Polunin, A. C. Mill, and N. A. J. Graham, "Size structural change in lightly exploited coral reef fish communities: evidence for weak indirect effects," Canadian Journal of Fisheries and Aquatic Sciences, vol. 61, no. 3, pp. 466475, 2004.

[11] S. Jennings and N. V. C. Polunin, "Effects of fishing effort and catch rate upon the structure and biomass of Fijian reef fish communities," Journal of Applied Ecology, vol. 33, no. 2, pp. 400-412, 1996.

[12] T. D. Brewer, J. E. Cinner, A. Green, and J. M. Pandolfi, "Thresholds and multiple scale interaction of environment, resource use, and market proximity on reef fishery resources in the Solomon Islands," Biological Conservation, vol. 142, no. 8, pp. 1797-1807, 2009.

[13] J. E. Cinner and T. R. McClanahan, "Socioeconomic factors that lead to overfishing in small-scale coral reef fisheries of Papua New Guinea," Environmental Conservation, vol. 33, no. 1, pp. 73-80, 2006.

[14] G. R. Russ and A. C. Alcala, "Marine reserves: rates and patterns of recovery and decline of predatory fish, 1983-2000," Ecological Applications, vol. 13, no. 6, pp. 1553-1565, 2003.

[15] T. R. McClanahan and N. A. J. Graham, "Recovery trajectories of coral reef fish assemblages within Kenyan marine protected areas," Marine Ecology Progress Series, vol. 294, pp. 241-248, 2005.

[16] S. K. Wilson, R. Fisher, M. S. Pratchett et al., "Habitat degradation and fishing effects on the size structure of coral reef fish communities," Ecological Applications, vol. 20, no. 2, pp. 442-451, 2010.

[17] G. P. Jones, M. I. McCormick, M. Srinivasan, and J. V. Eagle, "Coral decline threatens fish biodiversity in marine reserves," Proceedings of the National Academy of Sciences of the United States of America, vol. 101, no. 21, pp. 8251-8253, 2004. 
[18] S. R. Holzwarth, E. E. DeMartini, R. E. Schroeder, B. J. Zgliczynski, and J. L. Laughlin, "Sharks and jacks in the Northwestern Hawaiian Islands from towed-diver surveys 2000-2003," Atoll Research Bulletin, no. 543, pp. 257-279, 2006.

[19] R. E. Schroeder, M. S. Trianni, K. A. Moots, et al., "Status of fishery target species on coral reefs in the Mariana Archipelago," in Proceedings of the 10th International Coral Reef Symposium, Okinawa, Japan, 2006.

[20] P. Houk and J. Starmer, "Constraints on the diversity and distribution of coral-reef assemblages in the volcanic Northern Mariana Islands," Coral Reefs, vol. 29, no. 1, pp. 59-70, 2010.

[21] J. Miller, J. Maragos, R. Brainard, et al., "The state of Coral Reef Ecosystems of the Pacific Remote Island Areas," in The State of Coral Reef Ecosystems of the United States and Pacific Freely Associated States, J. E. Waddell and A. M. Clarke, Eds., NOAA Technical Memorandum NOS NCCOS 73, pp. 353-386, NOAA/NCOS Center for Coastal Monitoring and Assessment's Biogeography Team, Silver Spring, Md, USA, 2008.

[22] M. G. Sabater and B. P. Carroll, "Trends in reef fish population and associated fishery after three millennia of resource utilization and a century of socio-economic changes in American Samoa," Reviews in Fisheries Science, vol. 17, no. 3, pp. 318335, 2009.

[23] P. Craig, A. Green, and F. Tuilagi, "Subsistence harvest of coral reef resources in the outer islands of American Samoa: modern, historic and prehistoric catches," Fisheries Research, vol. 89, no. 3, pp. 230-240, 2008.

[24] S. O. Rohmann, J. J. Hayes, R. C. Newhall, et al., "The area of potential shallow-water tropical and subtropical coral ecosystems in the United States," Coral Reefs, vol. 24, no. 3, pp. 370-383, 2005.

[25] J. S. Ault, S. G. Smith, J. A. Bohnsack, J. Luo, D. E. Harper, and D. B. McClellan, "Building sustainable fisheries in Florida's coral reef ecosystem: positive signs in the dry tortugas," Bulletin of Marine Science, vol. 78, no. 3, pp. 633-654, 2006.

[26] R. Froese and D. Pauly, "FishBase," World Wide Web electronic publication. 2010, http://www.fishbase.org/search.php.

[27] M. Kulbicki, N. Guillemot, and M. Amand, "A general approach to length-weight relationships for New Caledonian lagoon fishes," Cybium, vol. 29, no. 3, pp. 235-252, 2005.

[28] Wm. L. Smith and M. T. Craig, "Casting the percomorph net widely: the importance of broad taxonomic sampling in the search for the placement of serranid and percid fishes," Copeia, no. 1, pp. 35-55, 2007.

[29] J. Dierking, Effects of the introduced predatory fish Cephalopholis argus on native reef fish populations in Hawaii, Ph.D. dissertation, Zoology Department, University of Hawaii at Manoa, Honolulu, Hawaii, USA, 2007.

[30] S. Jennings, J. D. Reynolds, and N. V. C. Polunin, "Predicting the vulnerability of tropical reef fishes to exploitation with phylogenies and life histories," Conservation Biology, vol. 13, no. 6, pp. 1466-1475, 1999.

[31] N. A. J. Graham, N. K. Dulvy, S. Jennings, and N. V. C. Polunin, "Size-spectra as indicators of the effects of fishing on coral reef fish assemblages," Coral Reefs, vol. 24, no. 1, pp. 118124, 2005.

[32] SAS, JMP 8.0.2., SAS Institute Inc, Cary, NC, USA, 2009.

[33] A. R. Henderson, "The bootstrap: a technique for datadriven statistics. Using computer-intensive analyses to explore experimental data," Clinica Chimica Acta, vol. 359, no. 1-2, pp. $1-26,2005$.
[34] M. A. MacNeil, N. A. J. Graham, N. V. C. Polunin et al., "Hierarchical drivers of reef-fish metacommunity structure," Ecology, vol. 90, no. 1, pp. 252-264, 2009.

[35] C. Mellin, C. J. A. Bradshaw, M. G. Meekan, and M. J. Caley, "Environmental and spatial predictors of species richness and abundance in coral reef fishes," Global Ecology and Biogeography, vol. 19, no. 2, pp. 212-222, 2010.

[36] C. Syms and G. P. Jones, "Disturbance, habitat structure, and the dynamics of a coral-reef fish community," Ecology, vol. 81, no. 10, pp. 2714-2729, 2000.

[37] H. A. Malcolm, S. D.A. Smith, and A. Jordan, "Using patterns of reef fish assemblages to refine a habitat classification system for marine parks in NSW, Australia," Aquatic Conservation: Marine and Freshwater Ecosystems, vol. 20, no. 1, pp. 83-92, 2010.

[38] M. G. Sabater and S. P. Tofaeono, "Scale and benthic composition effects on biomass and trophic group distribution of reef fishes in American Samoa," Pacific Science, vol. 61, no. 4, pp. 503-520, 2007.

[39] S. K. Wilson, R. Fisher, M. S. Pratchett et al., "Exploitation and habitat degradation as agents of change within coral reef fish communities," Global Change Biology, vol. 14, no. 12, pp. 2796-2809, 2008.

[40] T. R. McClanahan, N. A. J. Graham, J. M. Calnan, and M. A. MacNeil, "Toward pristine biomass: reef fish recovery in coral reef marine protected areas in Kenya," Ecological Applications, vol. 17, no. 4, pp. 1055-1067, 2007.

[41] G. R. Russ and A. C. Alcala, "Marine reserves: long-term protection is required for full recovery of predatory fish populations," Oecologia, vol. 138, no. 4, pp. 622-627, 2004.

[42] M. N. Lavides, N. V.C. Polunin, S. M. Stead, D. G. Tabaranza, M. T. Comeros, and J. R. Dongallo, "Finfish disappearances around Bohol, Philippines inferred from traditional ecological knowledge," Environmental Conservation, vol. 36, no. 3, pp. 235-244, 2009.

[43] D. R. Robertson, J. H. Choat, J. M. Posada, J. Pitt, and J. L. Ackerman, "Ocean surgeonfish Acanthurus bahianus. II. Fishing effects on longevity, size and abundance?" Marine Ecology Progress Series, vol. 295, pp. 245-256, 2005.

[44] P. B. Adams, "Life-history patterns in marine fishes and their consequences for fisheries management," Fishery Bulletin, vol. 78, no. 1, pp. 1-12, 1980.

[45] G. R. Russ and A. C. Alcala, "Natural fishing experiments in marine reserves 1983-1993: roles of life history and fishing intensity in family responses," Coral Reefs, vol. 17, no. 4, pp. 399-416, 1998.

[46] S. Jennings and N. V. Polunin, "Biased underwater visual census biomass estimates for target-species in tropical reef fisheries," Journal of Fish Biology, vol. 47, no. 4, pp. 733-736, 1995.

[47] M. Kulbicki, "How the acquired behaviour of commercial reef fishes may influence the results obtained from visual censuses," Journal of Experimental Marine Biology and Ecology, vol. 222, no. 1-2, pp. 11-30, 1998.

[48] F. A. Parrish and R. C. Boland, "Habitat and reef-fish assemblages of banks in the Northwestern Hawaiian Islands," Marine Biology, vol. 144, no. 6, pp. 1065-1073, 2004.

[49] I. D. Williams, W. J. Walsh, B. N. Tissot, and L. E. Hallacher, "Impact of observers' experience level on counts of fishes in underwater visual surveys," Marine Ecology Progress Series, vol. 310, pp. 185-191, 2006.

[50] A. A. Thompson and B. D. Mapstone, "Observer effects and training in underwater visual surveys of reef fishes," Marine Ecology Progress Series, vol. 154, pp. 53-63, 1997. 
[51] M. Kulbicki, N. Cornuet, L. Vigliola, L. Wantiez, G. Moutham, and P. Chabanet, "Counting coral reef fishes: interaction between fish life-history traits and transect design," Journal of Experimental Marine Biology and Ecology, vol. 387, no. 1-2, pp. 15-23, 2010.

[52] J. Colvocoresses and A. Acosta, "A large-scale field comparison of strip transect and stationary point count methods for conducting length-based underwater visual surveys of reef fish populations," Fisheries Research, vol. 85, no. 1-2, pp. 130-141, 2007.

[53] T. J. Willis, R. B. Millar, and R. C. Babcock, "Detection of spatial variability in relative density of fishes: comparison of visual census, angling, and baited underwater video," Marine Ecology Progress Series, vol. 198, pp. 249-260, 2000. 

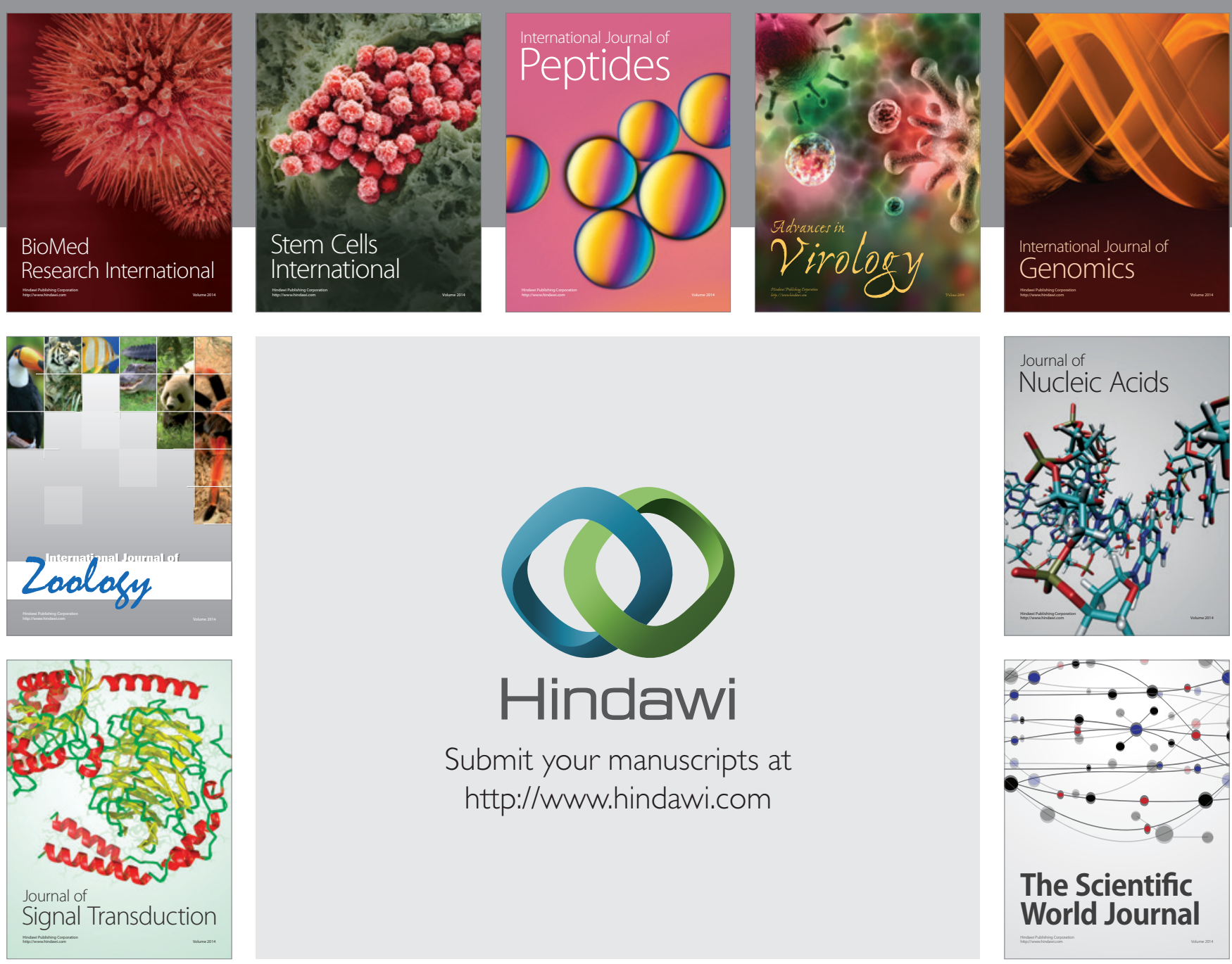

Submit your manuscripts at

http://www.hindawi.com
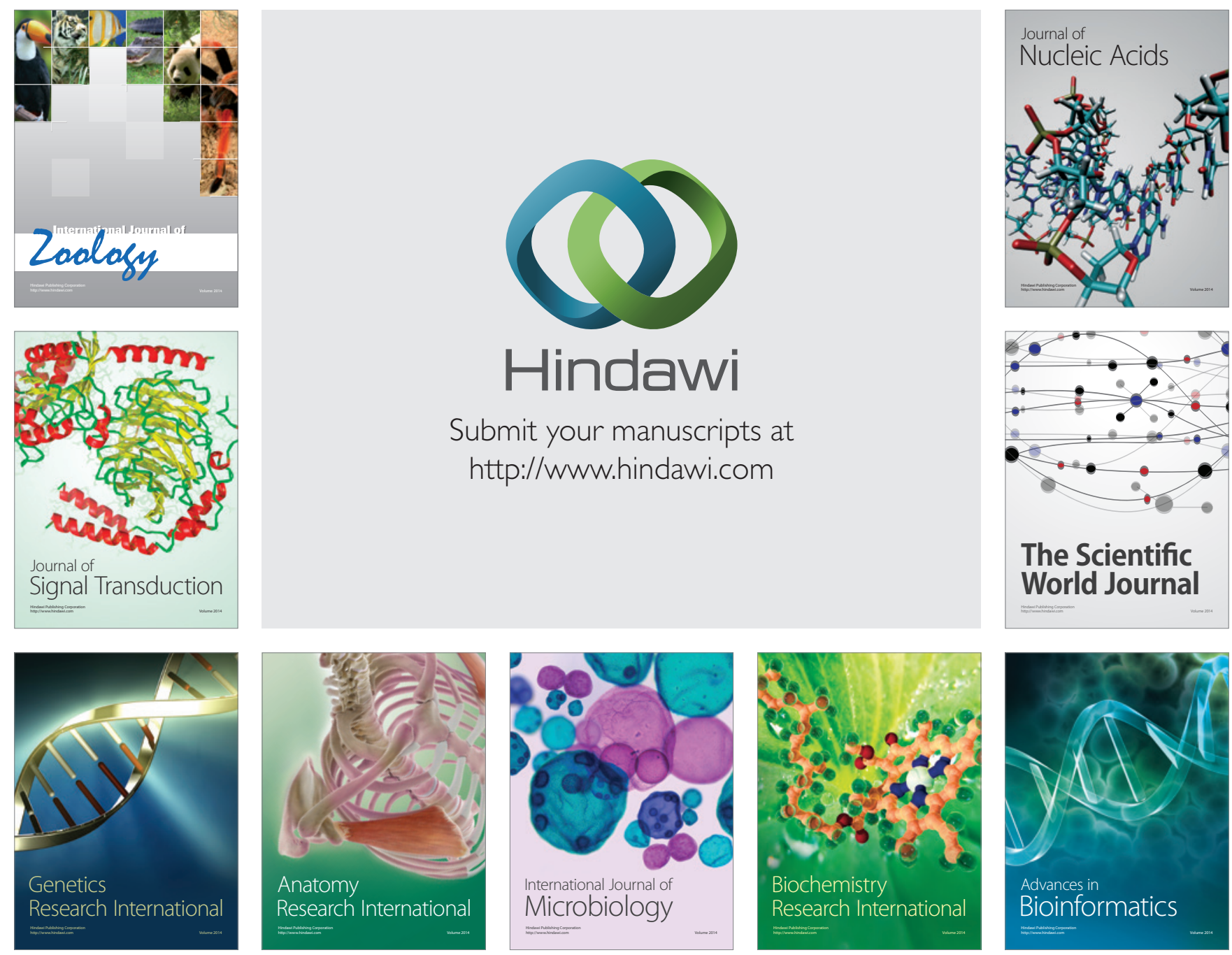

The Scientific World Journal
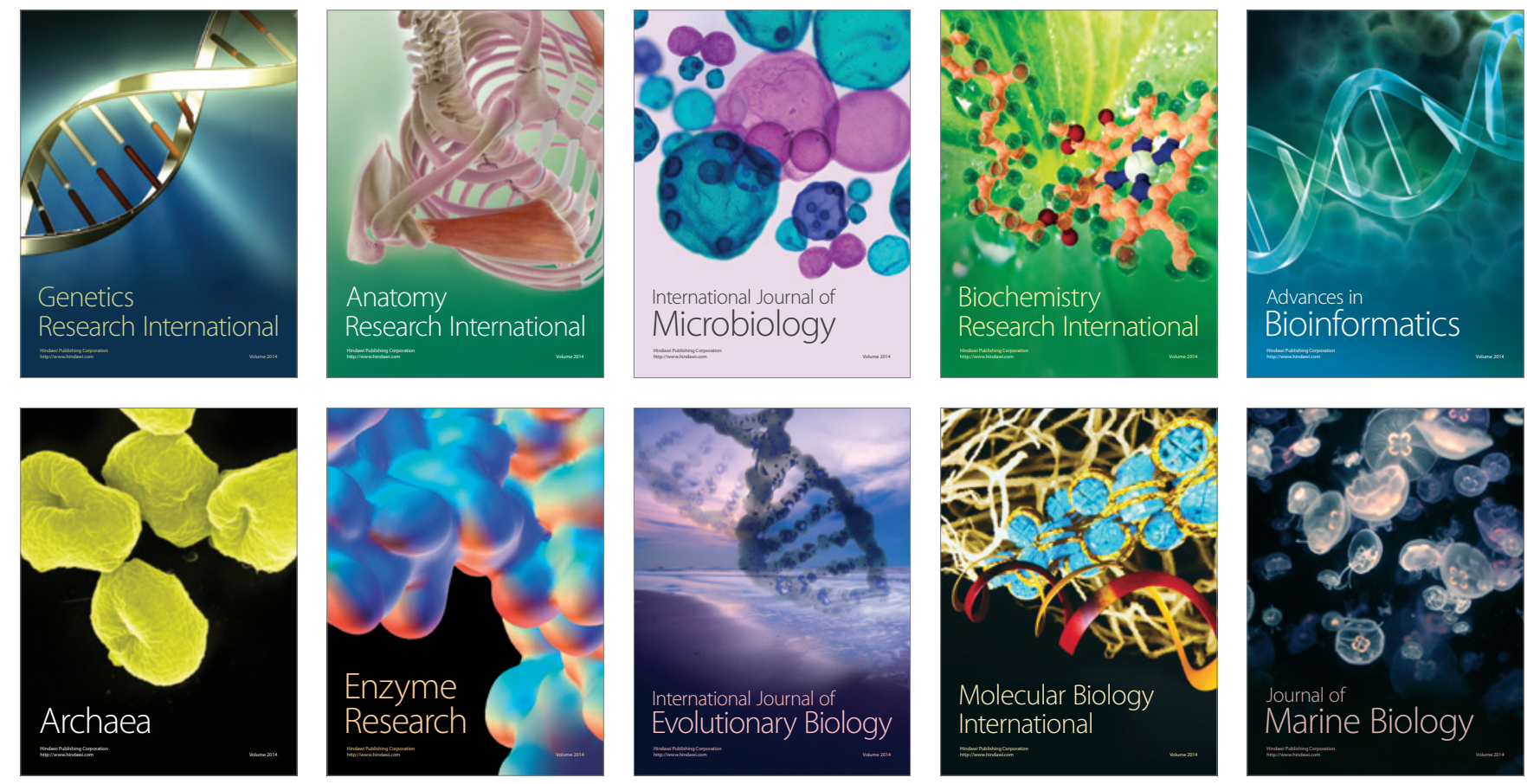